\title{
Variabilitas Arus Permukaan di Perairan Samudra Hindia Selatan Jawa
}

\author{
Yeyen Novita Sari ${ }^{1 *}$, Anindya Wirasatriya ${ }^{2}$, Kunarso $^{2}$, Baskoro Rochaddi ${ }^{2}$, Gentur Handoyo ${ }^{2}$ \\ ${ }^{l}$ Program Sarjana Departemen Oseanografi, Fakultas Perikanan dan Ilmu Kelautan \\ ${ }^{2}$ Departemen Oseanografi, Fakultas Perikanan dan Ilmu Kelautan, Universitas Diponegoro \\ J1. Prof.H.Soedarto S.H, Tembalang,Semarang, Jawa Tengah 50275 Indonesia \\ Email: *yeyen.nsari@gmail.com
}

\begin{abstract}
ABSTRAK
Arus laut merupakan sirkulasi dari pergerakkan massa air laut secara horizontal maupun vertikal dari satu lokasi ke lokasi yang lain untuk mencapai kesetimbangan dan terjadi secara kontinue. Letak geografis Selatan Jawa berada pada sistem angin munson yang menyebabkan kondisi oseanografi perairan dipengaruhi oleh sistem munson, serta dipengaruhi oleh anomali variabilitas iklim. Penelitian ini dilakukan dengan tujuan untuk mengetahui variasi musiman arus permukaan dan mekanisme pembentukan arus permukaan di Perairan Samudra Hindia Selatan Jawa. Penelitian ini menggunakan data model reanalisis arus permukaan Marine Copernicus tahun 2015. Data kemudian dianalisis dengan data pendukung Sea Level Anomaly dan angin Cross-Calibrated Multi Platform (CCMP) tahun 2015 yang diolah menggunakan Software IDL (Interactive Data Language) sehingga menghasilkan peta pola arus permukaan, peta Sea Level Anomaly, dan peta pola angin. Hasil penelitian ini menunjukkan variasi musiman arus permukaan musim barat dominan bergerak dari barat laut ke tenggara dengan kecepatan arus kuat ditepi samudra. Musim timur arus dominan bergerak menuju arah barat daya dan kecepatan arus kuat berada ditengah samudra, dan musim peralihan I dan peralihan II pola arus bergerak menuju barat daya dan kecepatan arus kuat berada ditengah samudra. Mekanisme pembentukan arus permukaan ditepi samudra dipengaruhi oleh gradien magnitudo SLA dengan nilai korelasi 0,523 dan ditengah samudra dipengaruhi oleh angin dengan nilai 0,636 .
\end{abstract}

Kata kunci : Angin, Arus Permukaan Laut, Perairan Selatan Jawa, Sea Level Anomaly

\section{ABSTRACT}

Sea currents are the circulations of seawater mass movement horizontally or vertically from one location to another to reach the equilibrium and occur continuously. The geographical position of South Java is in the Munson wind system that causing the marine oceanographic ocean conditions was affected by the Munson system, and also affected by anomaly in climate variability. This research was conducted to find out seasonal variations in surface currents and the mechanism of surface current formation in the Indian Ocean of the South Java. This research using theMarine Copernicus surface current reanalysis model data in 2015. Then the data is then analyzing with supporting data of Sea Level Anomaly and 2015 Cross-Calibrated Multi-Platform (CCMP) wind which is processed using IDL Software (Interactive Data Language) to produce a map of surface current patterns, Sea Level Anomaly maps, and wind pattern maps. The results of this research show that seasonal variations in the surface currents of the dominant west season move from the northwest to the southeast with strong currents at the edge of the ocean. The east monsoon dominant current moves towards the southwest and the speed of the strong currents is in the middle of the ocean, and the transitional season I and transition II pattern of the current pettern moves towards the southwest and the speed of the strong currents is in the middle of the ocean. The mechanism of the surface currents information is on the edge of the ocean is influenced by the magnitude gradient of the SLA with a correlation value of 0,523 and in the middle of the oceaninfluenced by the wind with a value of 0,636.

Keyword : Sea Level Anomaly, Sea Surface Currents, South Java Water, Wind

\section{PENDAHULUAN}

Arus laut merupakan sirkulasi dari pergerakkan massa air laut secara horizontal maupun vertikal dari satu lokasi ke lokasi yang lain untuk mencapai kesetimbangan dan terjadi secara kontinu. Gerakkan air di permukaan laut terutama disebabkan oleh adanya angin yang bertiup diatasnya, dan dipengaruhi juga oleh faktor lain selain angin, antara lain bentuk topografi dasar laut, daratan mengelilingi lautan, 
serta gaya Coriolis. Arus permukaan disebabkan oleh adanya angin yang bertiup diatasnya. Tenaga angin yang memberikan pengaruh terhadap arus permukaan sekitar $2 \%$ dari kecepatan air angin itu sendiri (Yani dan Ruhimat, 2007). Tetapi karena pengaruh rotasi bumi atau pengaruh gaya Coriolis, arus tidak bergerak searah dengan arah angin tetapi dibelokkan ke arah kanan dari arah angin di belahan bumi Utara dan arah kiri di belahan bumi Selatan (Azis, 2006).

Di wilayah Indonesia dikenal 2 jenis angin musim yang memiliki pengaruh besar terhadap pergerakan arus yaitu angin Musim Barat dan angin Musim Timur (Wyrtki, 1961). Pergerakan angin akan mempengaruhi karakteristik massa air di laut, salah satunya adalah terjadinya perubahan arah arus permukaan. Pergerakan angin yang kencang juga dapat mempengaruhi terjadinya percampuran massa air pada lapisan atas yang mengakibatkan sebaran suhu menjadi homogen (McPhaden dan Hayes, 1991).

Anomali tinggi muka laut adalah besarnya penyimpanan yang terjadi terhadap kondisi rata-rata tinggi muka laut (Marpaung dan Prayogo, 2014).

Letak geografis Selatan Jawa yang berada pada sistem angin monsun yang menyebabkan kondisi oseanografi perairan dipengaruhi oleh sistem monsun (Wyrtki, 1961), serta dipengaruhi oleh anomali variabilitas iklim seperti El Nino dan Ocean Dipole Mode (Shinoda, 2004). Perairan Selatan adalah perairan yang kompleks maka dari pada itu dalam penelitian ini akan dikaji tentang variasi musiman arus permukaan dan mekanisme pembentuk arus permukaan di Perairan Samudra Hindia Selatan Jawa.

Tujuan penelitian yaitu mengetahui variasi musiman dan mekanisme pembentukan arus permukaan di perairan Samudra Hindia Selatan Jawa.

\section{MATERI DAN METODE}

Materi yang digunakan pada penelitian ini terdiri data arus permukaan dan sea level anomaly yang diunduh dari situs http://marine.copernicus.eu, data angin yang diunduh website http//:remss.com selama periode pengamatan dari Januari 2015 sampai Desember 2015 dan semua data memiliki grid reguler $0,25^{\circ}$. Metode penelitian yang digunakan yaitu metode kuantitatif, yang dibagi atas beberapa tahapan yaitu studi literatur, penentuan lokasi penelitian, pengumpulan data, pengolahan dan analisis data.

\section{Metode Pengolahan Data Arus Permukaan}

Pengolahan data arus permukaan dalam bentuk sebaran spasial lalu diolah menggunakan Software pemrograman yang bertujuan untuk melihat fenomena variabilitas pola arah dan kecepatan arus permukaan. Semua data harian arus permukaan diubah dalam bentuk rata-rata bulanan dan nantinya didapatkan komponen zonal $u$ (Timur - Barat) dan $v$ (Utara - Selatan).

Dalam menghitung kecepatan dan arah arus permukaan digunakan juga persamaan :

Arah angin:

$$
V=\sqrt{u^{2}+v^{2}}
$$

$$
\begin{gathered}
\Theta=90-\tan ^{-1} \frac{u}{v} ; u>0, v>0 \\
90+\tan ^{-1} \frac{u}{v} ; u>0, v<0 \\
270-\tan ^{-1} \frac{u}{v} ; u>0, v>0 \\
270+\tan ^{-1} \frac{u}{v} ; u<0, v>0
\end{gathered}
$$

Dimana:

$u=$ Komponen arus zonal $(\mathrm{m} / \mathrm{s})$

$v=$ Komponen arus meridional $(\mathrm{m} / \mathrm{s})$

$V=$ Kecepatan total $(\mathrm{m} / \mathrm{s})$

$\Theta=$ Arah arus

\section{Metode Pengolahan Data Sea Level Anomaly}

Pengolahan citra satelit altimetri dalam bentuk sebaran spasial Sea Level Anomaly lalu dioleh dengan menggunakan Software pemrograman yang bertujuan untuk melihat sebaran SLA di perairan Samudra Hindia Selatan Jawa dan dapat mengetahui mekanisme pembentukan arus permukaan di perairan Samudra Hindia Selatan Jawa,. Data SLA harian diubah bentuk rata-rata bulanan, lalu dihitung 
perbedaan kemiringan tekanan dari SLA menggunakan rumus phytagoras, untuk mengetahuai sebaran gradien magnitudo SLA. Untuk mengetahui variabilitas temporal dilakukan dengan mengambil tampilan melintang pada koordinat lintang tertentu di setiap bulan yang mewakili Perairan Samudra Hindia Selatan Jawa.

\section{Metode Pengolahan Data Angin}

Pengolahan data angin dari CCMP dalam bentuk sebaran spasial yang lalu diolah menggunakan Software pemrograman yang bertujuan untuk melihat fenomena variabilitas pola arah dan kecepatan angin dan dapat mengetahui mekanisme pembentuka arus permukaan di perairan Samudra Hindia Selatan Jawa. Data angin harian diubah dalam bentuk rata-rata bulanan.

\section{HASIL DAN PEMBAHASAN}

Berdasarkan hasil olahan data Gambar 2 menunjukkan Musim Barat pola arus permukaan bergerak dari Barat Laut menuju Tenggara, dengan kecepatan arus permukaan kuat berada di wilayah tepi samudra Selatan Jawa Tengah sampai Jawa Timur dengan kecepatan 0,1 m/s smpai $0,6 \mathrm{~m} / \mathrm{s}$ (Gambar 2).

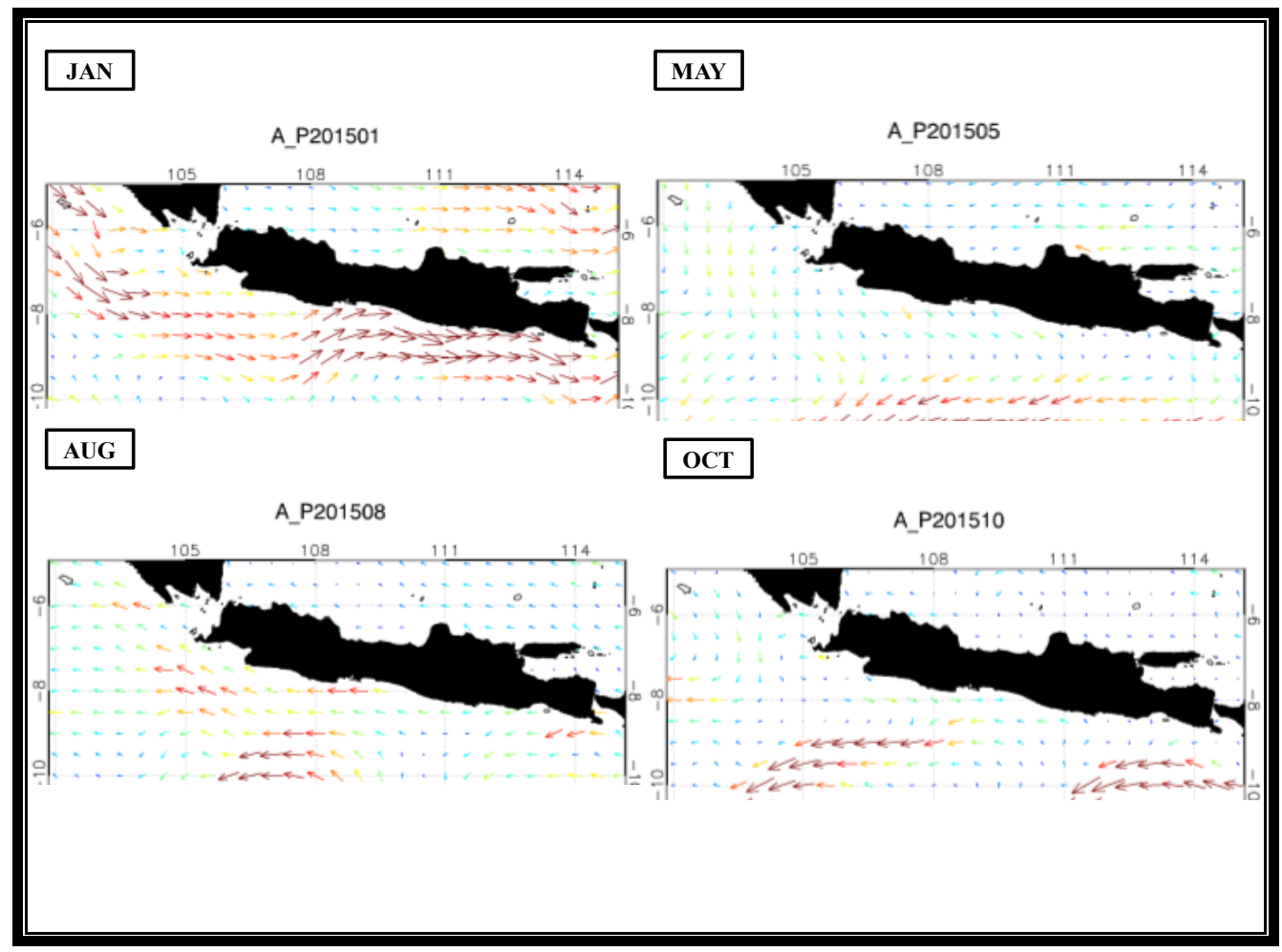

Gambar 2. Pola arus permukaan pada puncak 4 musim tahun 2015.

Hasil ini sesuai dengan Daruwedho et al., (2016) menyatakan bahwa Musim Barat arus permukaan bergerak dari Barat menuju Timur, hal ini terjadi karena angin Musim Barat bergerak dari benua Asia menuju benua Australia dengan kecepatan angin sebesar 5,7 m/s (Gambar 3), hal ini disebabkan karena belahan bumi selatan khususnya Australia lebih banyak memperoleh pemanasan matahari daripada benua Asia yang menyakibatkan benua Australia bertekanan rendah dan benua Asia bertekanan tinggi (Wilopo, 2005).

Perbedaan tekanan ini menggerakkan angin dari Barat menuju Timur. Pergerakkan angin akan menyuplai energi kinetik dan mendorong air di permukaan laut sehingga arah gerakkannya sesuai dengan arah arus. Tetapi karena pengaruh gaya Coriolis, sehingga arah gerak arus dibelokkan $45^{\circ}$ dari arah angin. Angin bergerak dari Barat menuju Timur menyakibatkan massa air juga terdorong bergerak dari wilayah Barat ke arah Timur, sehingga terjadi penumpukan massa air di wilayah tepi samudra (Gambar 4) dengan nilai gradien magnitudo SLA sebesar 0,4 dm. Karena adanya penumpukan massa 
air di wilayah tepi samudra menyebabkan kecepatan arus permukaan lebih kuat di wilayah tepi samudra dibandingkan wilayah tengah samudra, hal ini juga sesuai dengan pendapat Marpaung dan Harsanugraha (2014).

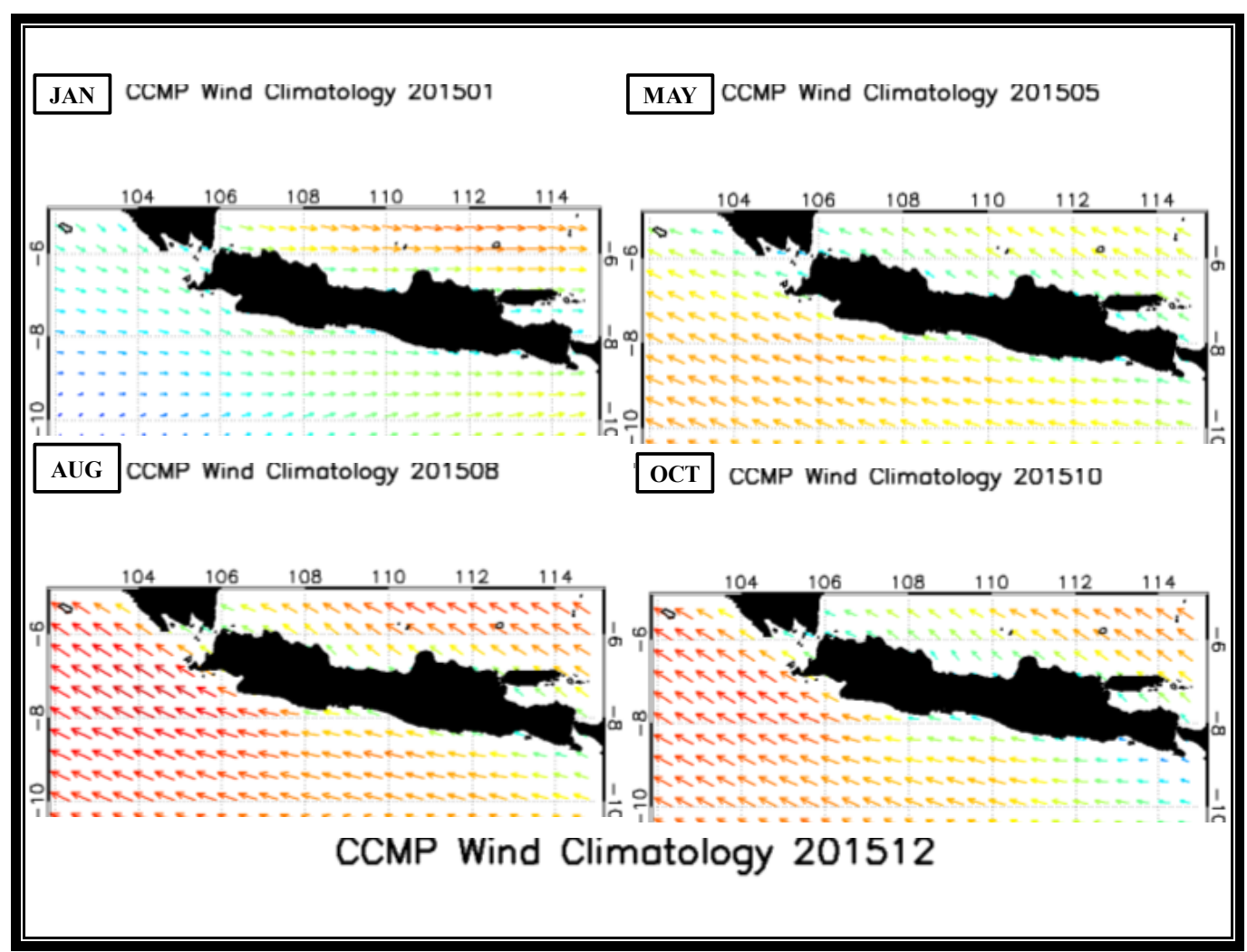

Gambar 3. Pola angin pada puncak 4 musim tahun 2015.

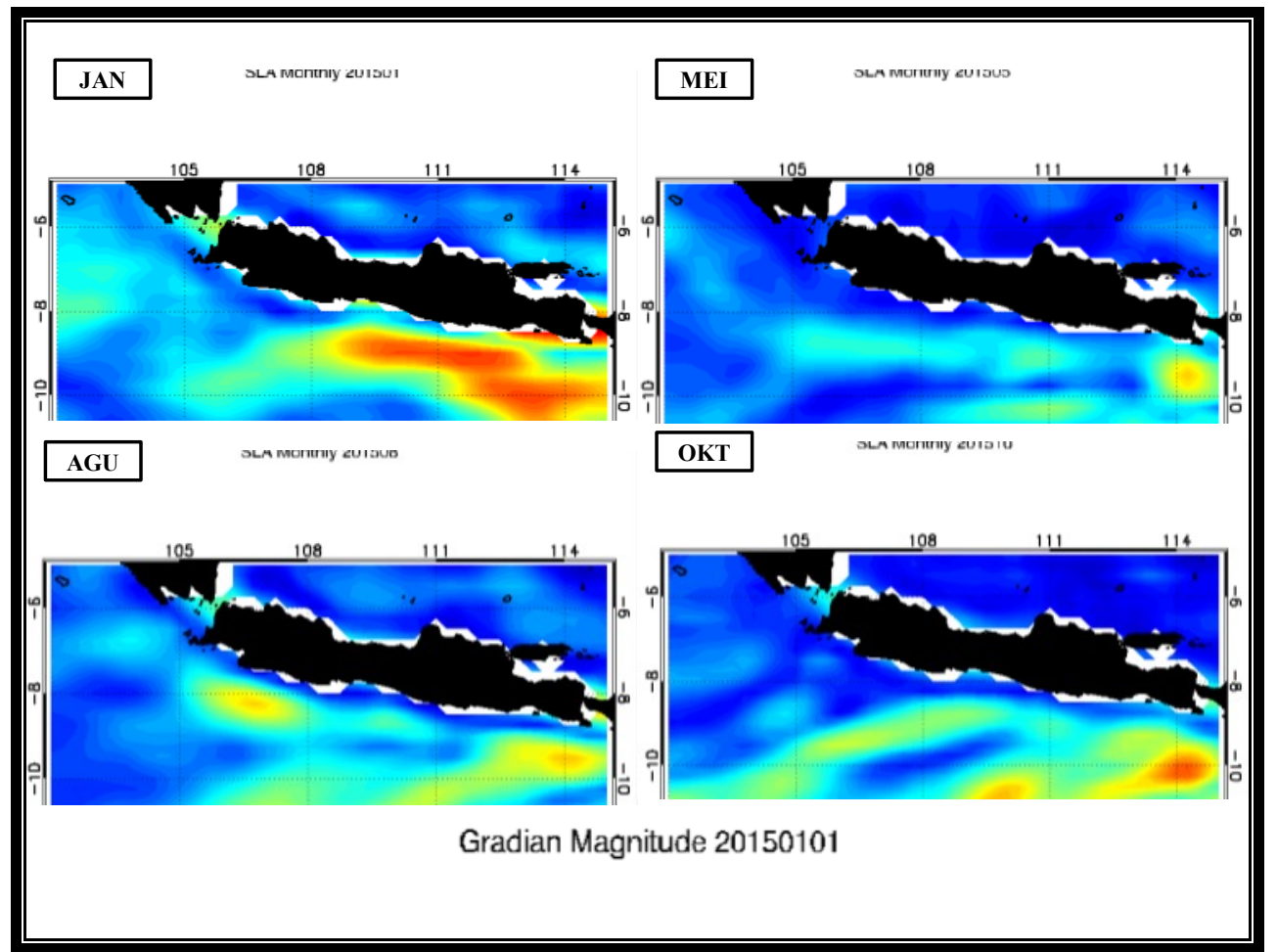

Gambar 4. Pola Gradien Magnitudo SLA Pada Puncak Musim Tahun 2015. 
Hubungan antara arus permukaan dengan angin dan gradien magnitudo SLA terlihat pada hasil analisis temporal dalam Gambar 6 kecepatan masing-masing parameter mencapai puncaknya pada bulan Januari, Juni, dan Januari di wilayah tepi samudra, sedangkan di wilayah tengah samudra pada bulan Oktober, Juni, dan Desember. Hubungan korelasi antara arus permukaan dan gardien magnitudo SLA di wilayah tepi samudra dan wilayah tengah samudra yaitu 0,523 dan 0,152 . Sedangkan hubungan arus permukaan dengan angin di wilayah tepi samudra dan tengah samudra yaitu 0,160 dan 0,636 (Tabel 1). Hubungan korelasi antara arus permukaan dan angin memiliki hubungan cukup tinggi di wilayah tengah samudra, hasil korelasi ini diperkuat dengan hasil penelitian Azis (2006) menyatakan bahwa arus permukaan digerakkan oleh angin yang bertiup pada permukaan laut.

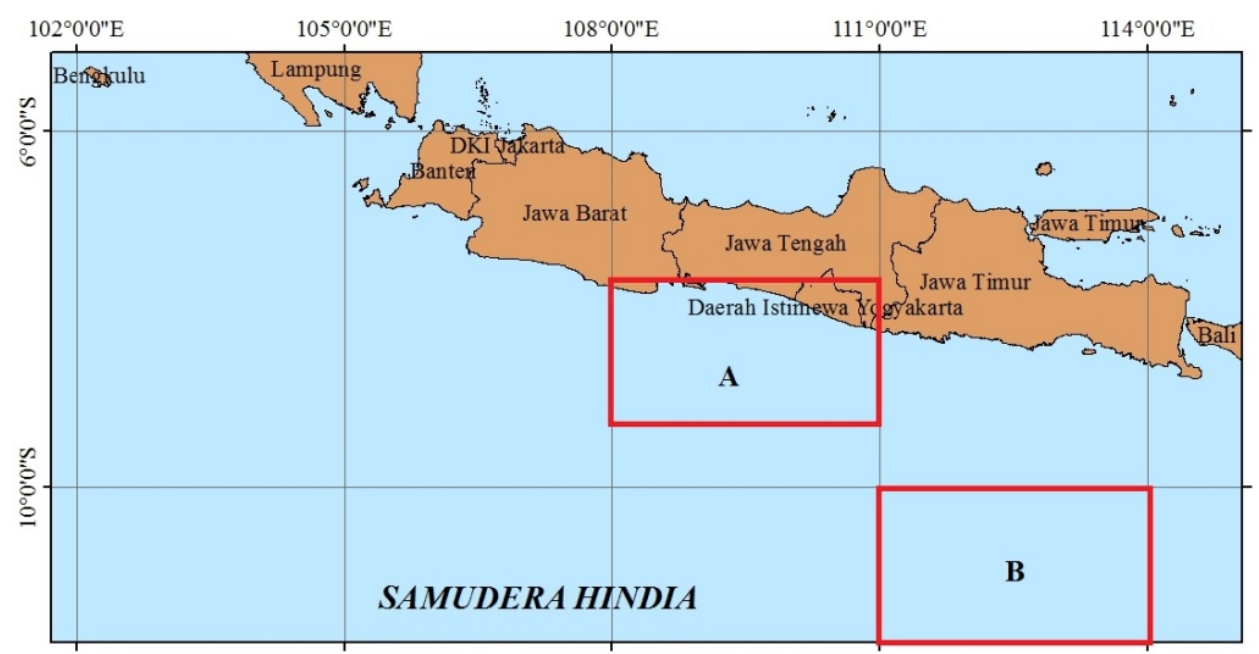

Gambar 5. Daerah Uji Penelitian.
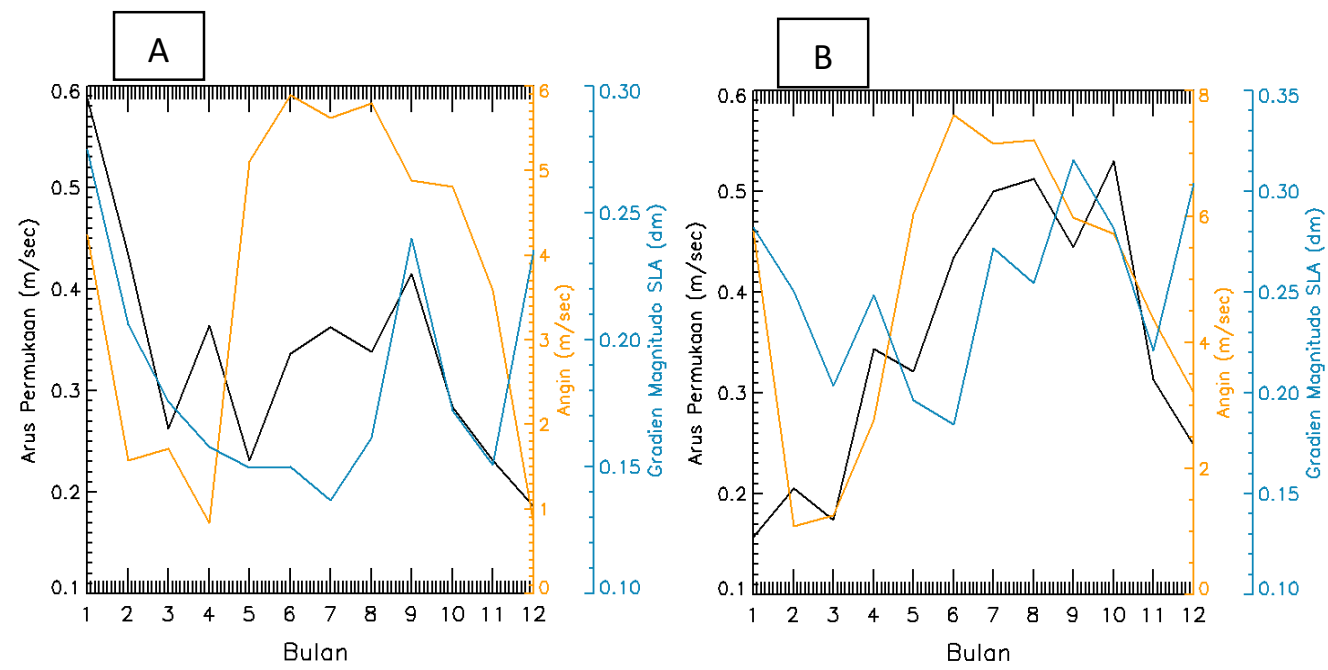

Gambar 6. (a) Grafik perbandingan arus permukaan, angin dan gradien magnitudo SLA Lokasi A. (b) grafik perbandingan arus permukaan, angin dan gradien magnitudo SLA Lokasi B. 
Tabel 1. Korelasi hubungan antar parameter (a) Lokasi A dan (b) Lokasi B

\begin{tabular}{|c|c|c|c|}
\hline A & $\begin{array}{l}\text { Arus } \\
\text { Permukaan }\end{array}$ & Angin & $\begin{array}{l}\text { Gradien } \\
\text { Magnitudo SLA }\end{array}$ \\
\hline Arus Permukaan & 1 & & \\
\hline Angin & 0,160 & 1 & \\
\hline $\begin{array}{l}\text { Gradien Magnitudo } \\
\text { SLA }\end{array}$ & 0,523 & $-0,268$ & 1 \\
\hline B & $\begin{array}{l}\text { Arus } \\
\text { Permukaan }\end{array}$ & Angin & $\begin{array}{l}\text { Gradien } \\
\text { Magnitudo SLA }\end{array}$ \\
\hline Arus Permukaan & 1 & & \\
\hline Angin & 0,636 & 1 & \\
\hline $\begin{array}{l}\text { Gradien Magnitudo } \\
\text { SLA }\end{array}$ & 0,152 & 0,039 & 1 \\
\hline
\end{tabular}

Pada Musim Timur pola arus permukaan dominan bergerak menuju arah Barat Daya (Gambar 2). Arus permukaan yang dibangkitkan oleh angin, terlihat dalam (Gambar 3) angin yang berhembus dari Tenggara menuju Barat Laut dengan kecepatan $7,6 \mathrm{~m} / \mathrm{s}$, tetapi karena adanya gaya Coriolis menyebabkan arah arus permukaan dibelokkan. Pembelokkan ini menyebabkan arah arus permukaan bergerak menuju Barat Daya, hal ini sesuai dengan penelitian Martono (2017).

Kecepatan arus permukaan di wilayah tengah samudra lebih kuat dibandingkan di wilayah tepi samudra yaitu $0,4 \mathrm{~m} / \mathrm{s}$ (Gambar 2). Karena arus permukaan bergerak dari tekanan tinggi menuju tekanan rendah, hal ini dapat dilihat dalam Gambar 4 tekanan permukaan laut tinggi terjadi di wilayah tengah samudra yaitu $0,35 \mathrm{dm}$, sedangkan di wilayah tepi samudra rendah yaitu $0,1 \mathrm{dm}$, hasil penelitian ini sama dengan Marpaung dan Prayogo, 2014 menyatakan anomali tinggi muka laut Musim Timur di laut lepas lebih tinggi dibandingkan di wilayah pantai. Perbedaan tekanan permukaan laut ini terjadi karena adanya hembusan angin sejajar pantai dan menyebabkan kekosongan di wilayah tepi samudra, sedangkan di wilayah tengah samudra terjadi penumpukan massa air dan membangkitkan arus permukaan, mekanisme ini sesuai dengan hasil penelitian Hadi dan Radjawane (2009) dalam Dimas et al., (2015).

Musim peralihan I pola arus permukaan bergerak menuju Barat Daya (Gambar 2 pada bulan mei), hal ini disebabkan karena pengaruh angin Musim peralihan I. Pergerakkan angin Musim Peralihan I bergerak menuju Barat Laut, tetapi karena adanya pengaruh gaya Coriolis menyebabkan arah gerak arus dibelokkan $45^{\circ}$, sehingga arah arus ke Barat Daya.

Sedangkan kecepatan arus permukaan Musim Peralihan I di wilayah tepi samudra $\left(9^{\circ}-10^{\circ} \mathrm{LS}\right.$, $\left.108^{\circ}-111^{\circ} \mathrm{BT}\right)$ lemah dengan kecepatan $0,2 \mathrm{~m} / \mathrm{s}$ dibandingkan di wilayah tengah samudra $\left(11^{\circ}-12^{\circ} \mathrm{LS}\right.$, $\left.107^{\circ}-109^{\circ} \mathrm{BT}\right)$ yaitu sebesar $0,58 \mathrm{~m} / \mathrm{s}$ (Gambar 2). Fenomena ini diduga terjadi karena adanya pengaruh angin dan perbedaan gradien tekanan permukaan laut, sebab arus permukaan bergerak dari tekanan tinggi menuju tekanan rendah. Perbedaan tekanan permukaan laut terlihat dalam Gambar 4, perbedaan gradien yang lebih tinggi ditengah samudra dengan kecepatan angin yang hampir sama diduga dapat membangkitkan kecepatan arus permukaan yang lebih kuat, dan sebaliknya.

Musim Peralihan II arus permukaan bergerak dari Timur menuju Barat Daya (Gambar 2), hal ini terjadi karena pengaruh pembangkit dari arus permukaan yaitu angin yang bergerak dari Tenggara menuju Barat Laut. Sedangkan kecepatan arus permukaan pada Musim Peralihan II di wilayah tepi samudra lebih lemah dibandingkan di wilayah tengah samudra mencapai $0,57 \mathrm{~m} / \mathrm{s}$. Perbedaan kecepatan ini diduga karena adanya pengaruh perbedaan tekanan, pada Gambar 4 terlihat di wilayah tepi samudra tekanan rendah yaitu $0,1 \mathrm{dm}$ sampai $0,2 \mathrm{dm}$, sedangkan di wilayah tengah samudra gradien magnitudo SLA kuat yaitu 0,3 dm sampai 0,4 dm, menyakibatkan arus permukaan bergerak menuju ketekanan yang rendah. Perbedaan tekanan permukaan laut diduga disebabkan karena adanya pengaruh angin yang 
bertiup pada Musim Peralihan II yang lemah (Gambar 3), pernyataan ini sesuai dengan Triadmodjo (2008).

\section{KESIMPULAN}

Variasi musiman arus permukaan di Perairan Samudra Hindia Selatan Jawa pada Musim Barat bergerak dari arah Barat Laut menuju Tenggara dengan kecepatan arus permukaan kuat berada ditepi samudra, Musim Timur arus permukaan bergerak menuju Barat Daya dengan kecepatan arus permukaan tengah samudra lebih kuat dibandingan ditepi samudra, sedangkan Musim Peralihan I dan II arus permukaan bergerak menuju Barat Daya dengan kecepatan arus permukaan kuat berada ditengah samudra. Mekanisme pembentukan arus permukaan di Perairan Samudra Hindia Selatan Jawa dipengaruhi oleh angin dan gradien magnitudo SLA. Arus permukaan dominan dipengaruhi oleh angin di wilayah tengah samudra dan di wilayah tepi samudra dominan dipengaruhi oleh gradien magnitudo SLA . Korelasi arus permukaan dengan angin di wilayah tepi samudra dan tengah samudra yaitu 0,160 dan 0,636, dan korelasi arus dan gradien magnitudo SLA di wilayah tepi samudra dan tengah samudra masing masing sebesar 0,523 dan 0,152 .

\section{DAFTAR PUSTAKA}

Azis, M.F. 2006. Gerak Air di Laut. Oseana, Volume XXXI (4). Hlm: 9 - 21.

Daruwedho, H., Sasmito, B., dan A, J, Fauzi. 2016. Analisis Pola Arus Laut Permukaan Perairan Indonesia Dengan Menggunkan Satelit Altimetri Jason-2 Tahun 2010-2014. Fakultas Teknik Geodesi. UNDIP. Vol 5. No 2.

Marpaung, S. dan T. Prayogo. 2014. Analisis Arus Geostropik Permukan Laut Berdasarkan Data Satelit Altimetri. LAPAN, Bandung.

Martono. 2017. Perubahan Tinggi Muka Laut Dan Kosentrasi Klorofil-A Di Perairan Selatan JawaSumbawa Selama Indian Ocean Dipole 2016. Lapan. Bandung.

McPhaden. and S. P. Hayes, 1991. On The Variability of Winds, Sea Surface Temperature, and Surface Layer Heat Content in The Western Wquatorial Pasific. J. Geosphys. Res. 96: 3331 - 3342.

R. Dimas, R., H. Setiyono dan M. Helmi. 2015. Arus Geostropik Permukaan Musiman Berdasarkan Data Satelit Altimetri Tahun 2012-2013 di Samudera Hindia Bagian Timur. Jurnal Oseanografi.Volume 4(4). Hlm: $756-764$.

Shinoda, T., Harry. H. Hendon, and M. A. Alexander. 2004. Surface and Subsurface Dipole Variability in The Indian Ocean and Its Relation with ENSO. Deep Sea Res.

Triatmodjo, Bambang. 2008. Hidrologi Terapan. Yogyakarta: Beta Offset.

Wilopo, D. M. 2005. Karakter Fisik Oseanografi Di Perairan Barat Semuatera Dan Selatan JawaSumbawa Dari Data Satelit Multi Sensor. Ilmu kelautan. IPB.

Wyrtki, K., 1961. PhysicalOcenography of the South East Asian Waters, Naga Report Vol.2 Scripps, Institute Oceanography, California.

Yani, A dan Ruhimat, M. 2007. Geologi. Bandung : Gralindo Media Pratama. 